\title{
HEMODYNAMIC PARAMETERS AND BRAIN OXYGENATION IN MILITARY PILOTS AS A FUNCTION OF ACCELERATION'S DURATION AT 4G AND AT 6G: A PRELIMINARY STUDY
}

\author{
Krzysztof KOWALCZUK' ${ }^{1}$ Liana PUCHALSKA², Hanna PALONEK ${ }^{3}$, Aleksander SOBOTNICKI ${ }^{4}$, \\ Michał JANEWICZ1 ${ }^{1}$, Mariusz WYLEŻOŁ' ${ }^{1}$, Stefan P. GAŹDZIŃSKI ${ }^{1}$ \\ ${ }^{1}$ Military Institute of Aviation Medicine, Warsaw, Poland \\ ${ }^{2}$ Warsaw Medical University, Warsaw, Poland \\ ${ }^{3}$ University of Mining and Technology, Krakow, Poland \\ ${ }^{4}$ Research Institute of Medical Technology, Zabrze, Poland
}

Source of support: The study was supported by the Inspectorate of Military Health Service (01/WNiL/2007).

\begin{abstract}
Author's address: K. Kowalczuk, M.D., Ph.D. DAvMed., Military Institute of Aviation Medicine, Krasińskiego 54/56 Street, 01-755 Warsaw, Poland, e-mail: kkowalczuk@wiml.waw.pl;

S. Gazdzinski, Ph.D. Military Institute of Aviation Medicine, Krasińskiego 54/56 Street, 01-755 Warsaw, Poland, e-mail: stefan.gazdzinski@yahoo.com
\end{abstract}

Introduction: Rapid onset and prolonged/sustained accelerations are often encountered in military aviation. The centrifugal force causes blood mass volume displacements. The pilot counters this phenomenon by means of anti-G straining manoeuvres (AGSM). However, the physiology of such prolonged manoeuvres is not clear. Here we have evaluated the effects of $4 \mathrm{G}$ and $6 \mathrm{G}$ accelerations lasting 10 s from $1.41 \mathrm{Gz}$ baseline on stroke volume (SV) and cardiac output (CO) and data quality, as well as changes in frontal brain oxygenation (OX) as a function of duration of the acceleration. We further compared the pilots' physiological responses to $4 \mathrm{G}$ and $6 \mathrm{G}$.

Methods: Ten military pilots (six active, with various amount of flight experience) performed the rapid onset rate (ROR) profile characterized by rapid onsets of $G z$ to $4 G$ and $6 G$ that lasted for 10 seconds, each without Anti-G trousers. The pilots' SV, CO were evaluated with bioimpedance cardiography, while their OX - with near infrared spectroscopy. ECG was constantly monitored.

Figures: 10 - Tables: 1 - References: 14 - Full-text PDF: http://www.pjambp.com • Copyright @ 2017 Polish Aviation Medicine Society, ul. Krasińskiego 54/56, 01-755 Warsaw, license WIML • Indexation: Index Copernicus, Polish Ministry of Science and Higher Education 
Results: SV and CO were generally decreasing with time, whereas HR was increasing. On average, SV was not different between 4G and 6G. However, CO and HR were significantly higher at $4 \mathrm{G}$ than at baseline $(\mathrm{p}<0.02)$, as well as they were higher at $6 \mathrm{G}$ than at $4 \mathrm{G}$ and baseline $(p<0.005)$. Despite that $O X$ on average was lower at $6 G$ than at $4 G$ than at baseline $(p<0.03)$. The data was of poorer quality and less of them were included in the numerical analyses for $6 \mathrm{G}$ than for $4 \mathrm{G}$, most likely due to the performed AGSM.

Discussion: Rapid onset acceleration leads to physiological adaptations that are more pronounced at $6 \mathrm{G}$ than at $4 \mathrm{G}$. There is some variability in the results due to the use of AGSM, which has a degrading effect on data quality.

Keywords: Hemodynamics, bioimpedance cardiography, $+\mathrm{Gz}$, monitoring, brain oxygenation

\section{INTRODUCTION}

We have previously evaluated the effects of gradual onset of $+\mathrm{Gz}$ on stroke volume (SV), cardiacoutput(CO) using impedance cardiography, and oxygenation saturation (OX) of frontal lobe using near infrared spectroscopy (NIRS) [1]. Rapid onset, prolonged/sustained accelerations are often encountered in military aviation. The pilot counters the blood mass volume displacements by means of anti-G straining manoeuvres (AGSM). The 4G acceleration (without Anti-G trousers) in general does not require the use of AGSM, whereas 6G most certainly does. However, it is not clear how long lasting accelerations affect the pilots' physiology. Here we have evaluated the effects of $4 \mathrm{G}$ and $6 \mathrm{G}$ accelerations lasting 10 s on SV, CO, and the quality of these measures, as well as changes in frontal brain oxygenation as a function of the duration of the acceleration.

\section{METHODS}

\section{Subjects}

Ten male military pilots (age: $34.8 \pm 8.2$ years; 24 47 years), with various amount of flight experience participated in the study. All subjects held a current fitness to fly certificate issued by the Aeromedical Board (i.e., they were healthy). All of them had normal or corrected-to-normal vision. The study protocol was approved in advance by the Bioethical Committee of the Military Institute of Aviation Medicine in Warsaw (Decision no 04/2014). Each subject provided written informed consent before participating and they were compensated for taking part in the experiment.

\section{Equipment}

A human centrifuge HTCO7 (AMST, Braunau, Austria) was used to produce the Gz. It was previously described in detail [1]. Mean blood oxygena- tion (both oxygenated and de-oxygenated blood) of the frontal lobe of the brain (OX) was measured using near infrared spectroscopy (NIRS; NellcorTM Pulse Oximetry, Covidien-Medtronic, Dublin, Ireland). OX was averaged in $4 \mathrm{~s}$ intervals. The optoelectronic detector (optode) was attached to the right side of the forehead of the pilot. Stroke volume (SV) and cardiac output (CO) were measured using electrical bioimpedance. A 3-channel experimental module ReoWir (ITAM, Zabrze, Poland) was used to measure electrical bioimpedance simultaneously in the thorax and in the neck [1]. Metrological parameters of the module were verified by using a dedicated simulator of resistive parameters of the tissues - ReoTester [2].

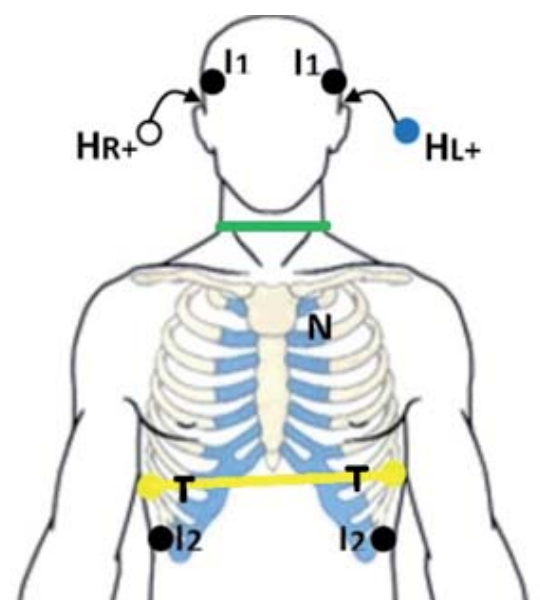

Fig. 1. Location of electrodes: Current electrodes: I1 placed on temples (gel electrodes), 12 placed on thorax (spring electrode), receiver electrodes $\mathrm{HI}+$ and $\mathrm{HR}+-$ behind the ears (gel electrode), $\mathrm{N}$ placed on the bottom of the neck (stainless wire spring electrode).

The location of electrodes on the pilot is depicted in figure 1. The bioimpedance signal from the thorax is collected using a standard electrode 
arrangement, as in Kubicek's method [3], but the location of the electrodes on the head is an original arrangement. Both NIRS and ReoWir were connected to the centrifuge system, thus the OX and bioimpedance signals were recorded synchronously with ECG, heart rate, Gz and saved in the centrifuge's data storing system. Then, all data were anonymized and exported for further processing on an external data processing station.

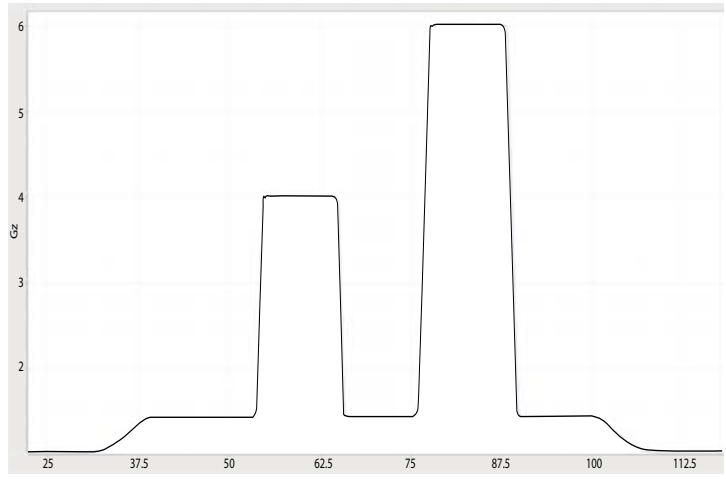

Fig. 2. Acceleration profile.

\section{Procedure}

The subjects were briefed on the study and its aims. Then ECG and bioimpedance leads were connected, and the NIRS optoelectronic detector was attached to the right side of the forehead. A Rapid Onset Rate (ROR) profile was selected, lasting 10 sec each.

\section{Calculation of stroke volume}

Stroke volume (SV) of the heart was calculated based on Kubicek's formula [4],

$$
S V=\operatorname{constant}\left(\frac{1}{z_{0}}\right)^{2}\left[\operatorname{LVET}\left(\frac{d z}{d t}\right)_{\max }\right]
$$

where $Z_{0}$ is the base impedance measured directly during the experiment.

The $Z_{0}$ values measured at the beginning of LVET were used for calculations. The leftventricular ejection time (LVET) and (dZ/dt)max were traced manually by two independent raters, trained and supervised by LP, who has extensive expertise in bioimpedance methods, as described previouisly [1]. Identified artefacts were excluded from analyses. SV and CO were calculated.

For the neck, only (dZ/dt)max was marked; it can be interpreted as the flow index in the carotid arteries $[5,6]$. The interclass correlation coefficient was higher than 0.7 for individual pilots. This result attests to good and very good reliability of the results. Similar results were obtained for CO calculated as SV.HR.

\section{Statistical Analysis}

The normality of distributions was evaluated automatically with appropriate tests. Student paired t-tests were utilized to evaluate the statistical significance of observed changes. We acknowledge that the bioimpedance signals were affected by artefacts created by the subject's breathing; however, these artefacts were added to the variability of measures obtained at particular conditions. All tests were performed with Statistica 13.1 software (Dell, Round Rock, TX, USA).

\section{RESULTS}

Fig. 3 - Fig. 10 illustrates the SV, CO, OX, and HR changes as a function of acceleration's duration at $4 \mathrm{G}$ and $6 \mathrm{G}$. Interpersonal variability is likely due to the use of AGSM that visibly deteriorates the signal, making it near impossible to reliably trace it. AGSM is used more at $6 \mathrm{G}$ than at $4 \mathrm{G}$, thus data for fewer pilots is available at the higher acceleration.

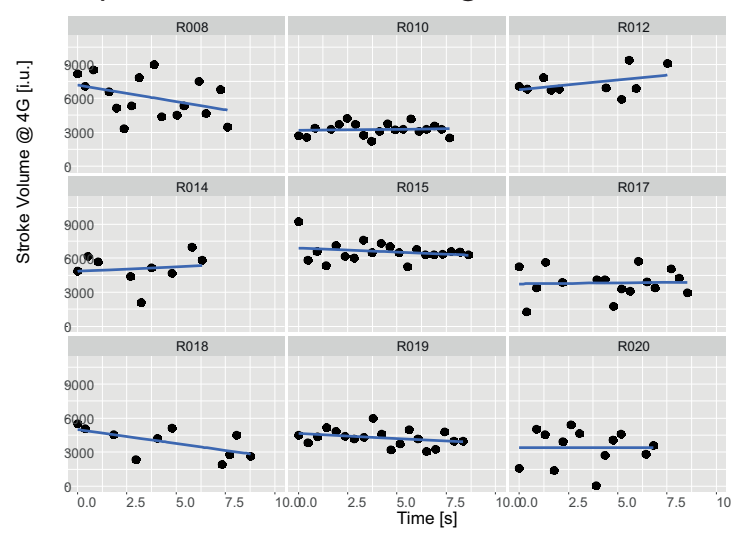

Fig. 3. Stroke volume changes with time at 4G. R008 - R020 indicate the consecutive pilots. Smaller numbers of measurements presented in some figures reflect lower quality of that data (need to exclude some measurements).

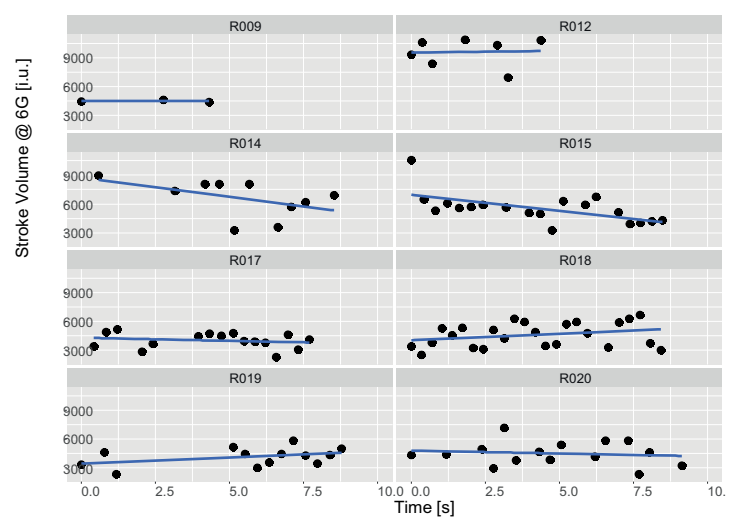

Fig. 4. Stroke volume changes with time at 6G. The lower number of data points (than at $4 \mathrm{G}$ ) reflects poorer data quality. Please note that in some cases all data points had to be removed due to poor quality. 


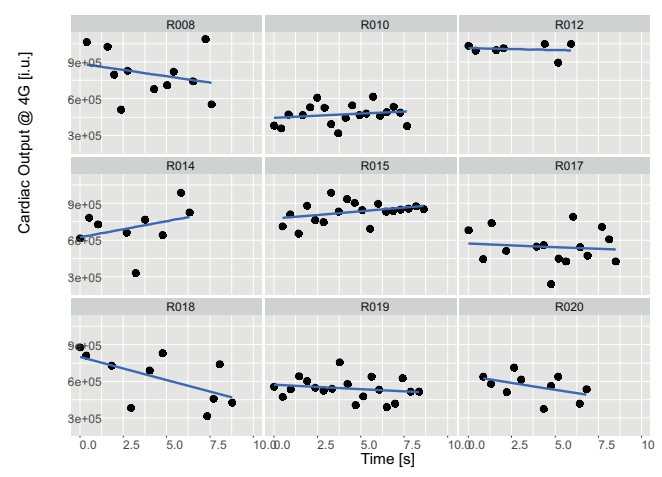

Fig. 5. Cardiac output changes with time at 4G.

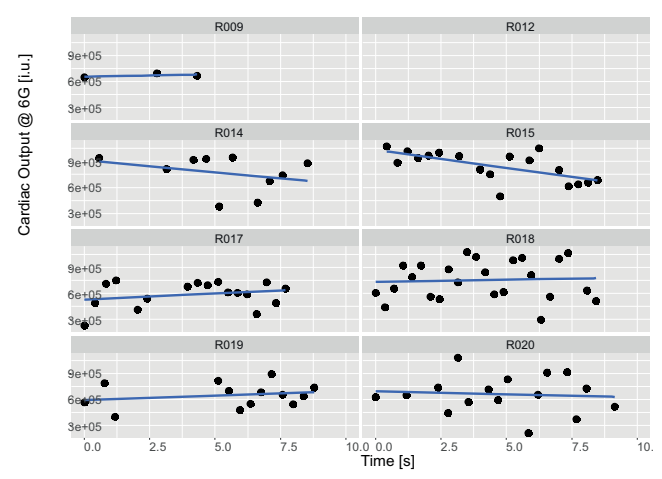

Fig. 6. Cardiac output changes with time at 6G.

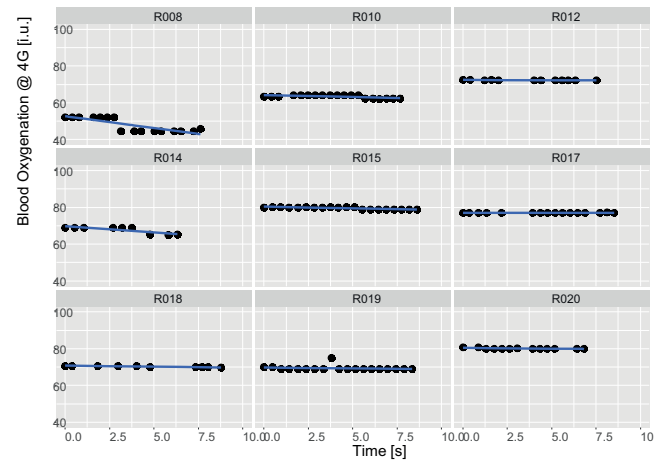

Fig. 7. Blood oxygenation (OX) changes with time at 4G.

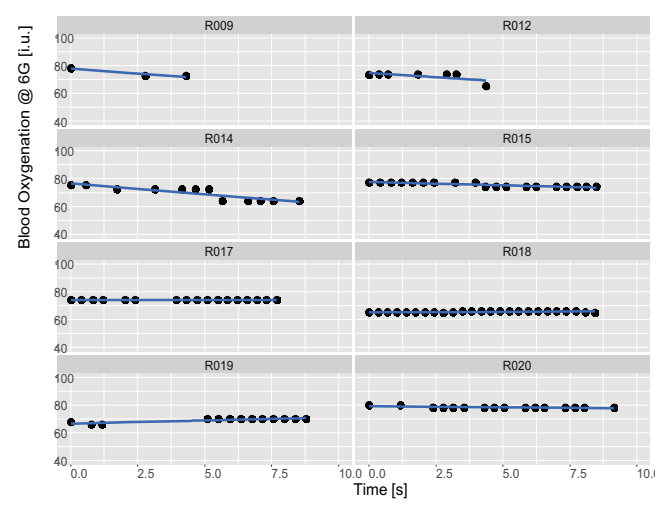

Fig. 8. Blood oxygenation (OX) changes with time at $6 \mathrm{G}$.

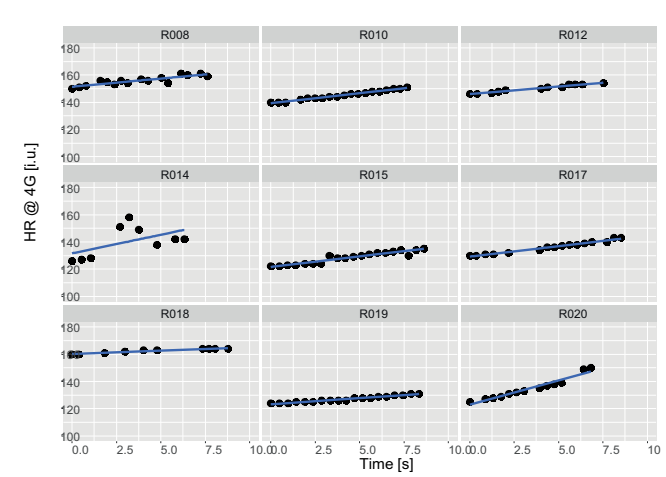

Fig. 9. Heart rate changes with time at $4 \mathrm{G}$.

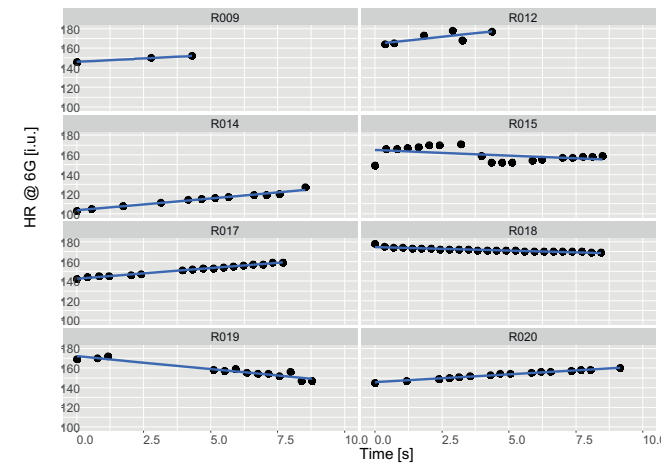

Fig. 10. Heart rate changes with time at $6 \mathrm{G}$.

Table 1 shows the changes in mean SV, CO, OX, and $H R$ between the baseline, 4G, and $6 \mathrm{G}$.

Tab. 1. Changes in parameters induced by increases of accelerations; a) from baseline 1,4G to $4 \mathrm{G}$, b) from $1,4 \mathrm{G}$ to $6 \mathrm{G}, \mathrm{c}$ ) from $4 \mathrm{G}$ to $6 \mathrm{G}$.

\begin{tabular}{lccc}
\hline \multirow{2}{*}{ Change in [\%] } & \multicolumn{3}{c}{ Change between [\%], and significance level, $\mathbf{p}$} \\
\cline { 2 - 4 } & Baseline and 4G & Baseline and 6G & 4G and 6G \\
\hline $\begin{array}{l}\text { Stroke Volume } \\
\text { (SV) }\end{array}$ & $9 \pm 25, \mathrm{~ns}^{*}$ & $16 \pm 34, \mathrm{~ns}^{*}$ & $7 \pm 20, \mathrm{~ns} \mathrm{~s}^{*}$ \\
\hline $\begin{array}{l}\text { Cardiac Output } \\
\text { (CO) }\end{array}$ & $22 \pm 24, \mathrm{p}=0.02$ & $41 \pm 23, \mathrm{p}=0.003$ & $16 \pm 10, \mathrm{p}=0.001$ \\
\hline Heart Rate (HR) & $14 \pm 12, \mathrm{p}=0.001$ & $26 \pm 14, \mathrm{p}=0.005$ & $9 \pm 14, \mathrm{p}=005$ \\
\hline $\begin{array}{l}\text { Blood Oxygena- } \\
\text { tion (OX) }\end{array}$ & $-1 \pm 2, \mathrm{p}=0.03$ & $-4 \pm 3, \mathrm{p}=0.003$ & $-2 \pm 3, \mathrm{p}=0.04$ \\
\hline \begin{tabular}{l} 
Flow Index \\
\hline
\end{tabular} & $-12 \pm 34, \mathrm{~ns}$ & $12 \pm 39, \mathrm{~ns}$ & $21 \pm 34, \mathrm{~ns}$ \\
\hline
\end{tabular}

*ns - stastistically non significant.

\section{DISCUSSION}

In this study, we have demonstrated that the physiological response to rapid onset accelerations changes with time. However, the picture is distorted by the use of AGSM. Higher value of the acceleration leads to larger mean changes in stroke volume, cardiac output, brain oxygenation and heart rate. No significant changes in flow index were found. 
However, larger G loads resulted in statistically significant decreases of brain frontal lobe oxygenation, most likely due to redistribution of the blood in the thorax; i.e. less blood ended up in the brain due to a larger gravitational field in the centrifuge. The additional $+\mathrm{Gz}$ effect that must be taken into consideration is air-blood mismatch in lungs under Gz [7-9].

All examined pilots were neither instructed to perform or withdraw from performing AGSM. However they performed the muscular component of AGSM without the breathing component. The breathing component of AGSM relies on intermittent increase of airway pressure which can at least partially alleviate Gz effects on the lungs. Rohdin et al. [10] also demonstrated decreased lung diffusion capacity in hypergravity. On the other hand, increases in base impedance of the neck with increasing $\mathrm{Gz}$ could be interpreted as decrease of the blood volume in the neck. However, the cranium acts as a rigid container of the brain, the cerebro-spinal fluid, and blood, which are virtually incompressible [11], thus the amount of blood in the brain is likely constant during the $+\mathrm{Gz}$ accelerations used in our study. Moreover, the cerebral autoregulation maintains a relatively constant cerebral blood flow within the range arterial blood pressure from about 60 to $150 \mathrm{mmHg}$ $[11,12]$. In our experience, arterial blood pressure may decrease below $60 \mathrm{mmHg}$ at $+6 \mathrm{G}$, thus smaller cerebral blood flow may contribute to decreases of $O X$ with increasing $+G z$.

Another thing worth consideration is venous return from brain. Under the $+\mathrm{Gz}$ load, blood tends to be pooled in the venous system of the lower extremities and the lower part of the abdomen. This othostatic effect may cause blood pressure in jugular veins to be lowered to almost zero, which may cause jugular veins to collapse and effectively stop the venous outflow from the brain. Some portions of blood "trapped" in parts of the brain may be further deoxygenated through the metabolism of the surrounding tissues, which can contribute to a decrease in the Ox results registered.

The above mentioned phenomena could be responsible for the small drop in brain oxygenation in our participants, despite significantly larger cardiac outputs at $6 \mathrm{G}$ than at $4 \mathrm{G}$.

We did not evaluate changes in arterial pressure and its relationship to the measured parameters. As it is known that ZO increases with bleeding induced hypotension in pigs [13], it is likely that changes in blood pressure would explain some variance in SV, CO, and OX.

Our results may help understand the physiological adaptations to hypergravity in commercial space flights, where the accelerations do not exceed $6 \mathrm{G}$ and the age of the prospective space travellers spans a wide range from 22 to 80 years [14]. Although the $\mathrm{G}$ loads in these voyages are not expected to exceed $4 G$, one should remember that military pilots are selected based on endurance and fitness. Thus, the physiological processes described in our study may take place at much lower accelerations in the general population. The nonzero resistance of the current electrodes applied in our study led to some limitations in the results, as it caused a slight overestimation of baseline impedances, but, it resulted in a slight underestimation of the reported changes in SV and CO. Similarly, the breathing artefacts had detrimental effects on fitting quality; however, it is unlikely it biased the regression results.

The conclusions are limited by the fact that the pilots performed straining at the onset of the acceleration and at various times of the overload.

\section{CONCLUSIONS}

Rapid onset acceleration led to physiological adaptations that are more pronounced at $6 \mathrm{G}$ than at $4 G$. There is some variability in the results due to the use of AGSM that has a degrading effect on data quality.

\section{AUTHORS' DECLARATION:}

Study Design: Krzysztof Kowalczuk, Liana Puchalska, Mariusz Wyleżoł, Stefan P. Gaździński; Data Collection and Analysis: Krzysztof Kowalczuk, Liana Puchalska, Hanna Palonek, Aleksander Sobotnicki, Michał Janewicz, Stefan P. Gaździński; Manuscript Preparation: Stefan P. Gaździński, Krzysztof Kowalczuk; Funds Collection: Mariusz Wyleżoł. The Authors declare that there is no conflict of interest. 
Original Article

\section{REFERENCES}

1. Kowalczuk K, Puchalska L, Sobotnicki A, Czerw M, Janewicz M, Wylezol M, et al. Effects of Gradual Onset +Gz on Hemodynamic Parameters and Brain Oxygenation in Military Pilots: Preliminary Study. The Polish Journal of Aviation Medicine, Bioengineering and Psychology. 2016; 22(3):5-11.

2. Piekar E, Sobotnicki A. The simulator of resistive parameters of the tissues for bioimpedance research. Measurement Automation and Monitoring. 2014; 60:1181-4.

3. Gujjar AR, Muralidhar K, Bhandopadhyaya A, Sathyaprabha TN, Janaki P, Mahalla BK, et al. Transthoracic electrical bioimpedence cardiac output: comparison with multigated equillibrium radionuclide cardiography. Journal of Clinical Monitoring and Computing. 2010; 24(2):155-9.

4. Sherwood A, Allen MT, Fahrenberg J, Kelsey RM, Lovallo WR, Vandoornen LP. Methodological guidelines for impedance cardiography. Psychophysiology. 1990; 27(1):1-23.

5. Stanley AWH, Jr., Herald JW, Athanasuleas CL, Jacob SC, Sims SW, Bartolucci AA, et al. Multi-channel electrical bioimpedance: a new noninvasive method to simultaneously measure cardiac and peripheral blood flow. Journal of clinical monitoring and computing. 2007; 21(6):345-51.

6. Khalil SF, Mohktar MS, Ibrahim F. The Theory and Fundamentals of Bioimpedance Analysis in Clinical Status Monitoring and Diagnosis of Diseases. Sensors. 2014; 14(6):10895-928.

7. Whinnery JE. +Gz tolerance correlation with clinical-parameters. Aviation Space and Environmental Medicine. 1979; 50(7):736-41.

8. Buick F, Hartley J, Pecaric M. Maximum intrathoracic pressure with anti-g straining maneuvers and positive pressure breathing during +Gz. Aviation Space and Environmental Medicine. 1992; 63(8):670-7.

9. Macdougall JD, McKelvie RS, Moroz DE, Moroz JS, Buick F. The effects of variations in the anti-g straining maneuver on blood-pressure at $+\mathrm{Gz}$ acceleration. Aviation Space and Environmental Medicine. 1993; 64(2):126-31.

10. Rohdin M, Petersson J, Sundblad P, Mure M, Glenny RW, LindahI SGE, et al. Effects of gravity on lung diffusing capacity and cardiac output in prone and supine humans. Journal of Applied Physiology. 2003; 95(1):3-10.

11. Rudzinski W, Swiat M, Tomaszewski M, Krejza J. Cerebral hemodynamics and investigations of cerebral blood flow regulation. Nuclear medicine review Central \& Eastern Europe. 2007; 10(1):29-42.

12. Koller A, Toth P. Contribution of Flow-Dependent Vasomotor Mechanisms to the Autoregulation of Cerebral Blood Flow. Journal of Vascular Research. 2012; 49(5):375-89.

13. Venugopal D, Patterson R, Jhanjee R, McKnite S, Lurie KG, Belalcazar A, et al. Subcutaneous Bioimpedance Recording: Assessment of a Method for Hemodynamic Monitoring by Implanted Devices. Journal of Cardiovascular Electrophysiology. 2009; 20(1):76-81.

14. Blue RS, Riccitello JM, Tizard J, Hamilton RJ, Vanderploeg JM. Commercial Spaceflight Participant G-Force Tolerance During Centrifuge-Simulated Suborbital Flight. Aviation Space and Environmental Medicine. 2012; 83(10):929-34

\section{ACKNOWLEDGEMENTS}

We would like to thank Mariusz Walas, Jan Lech, Krzysztof Król for technical assistance and Andrzej Gaździński for assistance in the computer programming needed for the data analyses.

Cite this article as: Kowalczuk K, Puchalska L, Palonek H, Sobotnicki A, Janewicz M, Wyleżoł M, Gaździński S. Hemodynamic Parameters and Brain Oxygenation in Military Pilots as a Function of Acceleration's Duration at 4G and at 6G: A Preliminary Study. Pol J Aviat Med Bioeng Psychol 2017; 23(2): 5-10. DOI: 10. 13174/ pjambp. 16. 07. 2018.01 